\title{
Social Statistics and Ethnic Diversity: Cross-national Perspectives in Classifications and Identity Politics
}

\author{
edited by Patrick Simon, Victor Piché, and Amélie A. Gagnon \\ New York: Springer, 2015 \\ ISBN: 978-3-319-20094-1 \\ Hardcover $\$ 59.99,244$ pp.
}

\section{Reviewed by Margot Almond}

Unaffiliated researcher (ret.)

The topic of ethnicity is a hot topic in public debate. Countries around the world are increasingly affected by cultural pluralism, as a result of trends such as rising demands for recognition by indigenous groups, new waves of immigration and refugee flows, and the post-colonial maturation of societies. It is no coincidence that issues around the measurement of ethnicity, and the impact of the policy discourse on how we measure it, are also emerging on the scientific radar screen.

This 12-chapter volume addresses some very topical issues in the measurement of ethnicity. The editors set out to address both how countries measure ethnic identity as well as why they measure it, and what factors affect the debate on measurement. The various articles in the book refer to a diverse set of concepts, including ethnic identity, ethnic ancestry, race, language, and religion. The book is largely composed of case studies of individual countries, provinces, or indigenous groups, preceded by two chapters of multi-national analyses. In that sense, the two approaches complement each other well, offering both macro and micro perspectives on the same issue.

This volume draws heavily on the "International Conference on Social Statistics and Ethnic Diversity: Should We Count, How Should We Count and Why?" held in 2007. Most of the articles are reworked versions of papers presented at the conference, some of which were subsequently published in various journals.

The writers are from around the world, most of them based in the country they are writing about, obviously contributing to their insights into the politics of the statistical debates, which span many decades. The nine case studies include countries in the Americas, Asia, and Europe, but oddly none in Africa, even though chapter 2 notes that at least eight African countries use some sort of ethnic measurement (p. 22).

The introductory chapter by the three editors very capably situates the book in context, and provides some of the theoretical underpinnings taken from earlier work. The two multi-national chapters explore completely different topics, with the first, by Ann Morning, being a survey of the ethnicity measurement practices of a sample of 138 nations. This covers the first theme of the book, which is "who" gets counted. One of the interesting aspects explored in this book is the fact that what we do not measure can say as much about a society as what we do measure. The typology of data collection regimes has a category for the large number of nations which do not measure ethnicity (35 per cent, according to Morning ${ }^{1}$ ). Several chapters discuss how nations opted NOT to count, or to count but not to publish, ethnicity data.

The second multi-national survey is by Kukutai and Thompson, and uses regression techniques to examine the second theme of the book, which is "why" we count. This chapter examines a series of internal variables (including ethnic claims, immigration, post-colonial sovereignty) and external factors (such as support for human rights instruments) to examine how the political environment influences the measurement of ethnicity.

1. Chapter 2, page 17. 
This volume builds on earlier work by Simon and Piché, including Accounting for Ethnic and Racial Diversity: The Challenge of Enumeration (2013). For example, the multi-national surveys on how and why countries measure ethnicity are now global in scope.

Although the influence of sociopolitical discussion on ethnicity measurement is explored in depth, the reverse - the influence of ethnic measurement and resulting statistics on the political conversation-is surprisingly only briefly mentioned by a few authors. For example, Piché argues that the introduction of the term "allophone" started a new political discourse that continues even today (p. 92). Thompson observes that joining the European Union significantly affected ethnicity measurement in Britain (p. 133), which might suggest to the reader that Britain exiting the EU will also have an impact. Perhaps this reverse impact will be the subject of a future work.

Chapters 4 to 7 are case studies dealing with the influence of the socio-political debates on how states measure ethnicity. Simon offers an interesting set of observations on the various arguments against ethnicity measurement that are part of the ongoing debate in France. The continued evolution of ethnicity statistics over a long period of time confirms that this is an issue to be watched in the future. The chapter on Britain by Debra Thompson offers some unique and fascinating behind-the-scenes insight into the decision making on question design at the most senior political levels.

The third part of the book consist of five case studies focusing on the interplay between competing identities and statistics. Three of those studies devote significant attention to the impact of the socio-political environments on statistics, and offer some very interesting insights. The Uruguayan case study ${ }^{2}$ is unique in that it is the only case study of a country where "racial identities are not frequently activated in everyday life" (p. 179), which might erroneously lead one to believe that there might be less social debate over such topics, and therefore less attention to ethnicity measurement. However this chapter, along with the chapter on the explosion in Aboriginal populations in Canada, ${ }^{3}$ both point out the impact of rising self-awareness of ethnic identity amongst indigenous populations. In addition, the Belgian case study ${ }^{4}$ emphasizes the impact of changing laws on Belgian citizenship on the counts of Belgian nationals; however, it does not go the extra step of examining the impact of the resulting data on the political debate.

The Malaysian case study ${ }^{5}$ is interesting in that it breaks from the norm and delves into the different definitions used in various government surveys, and how each of these constructs produces different statistical outcomes.

Although this volume deals with a somewhat subjective area for survey respondents, the topic of respondent confusion was not often discussed. For example, Debra Thompson made some interesting points about confusion among respondents in British field trials (for example in relation to terms such as "British Asian" and "Black British"; p. 124), while Morning (p. 27) and Guimond et al. (p. 230) mention it in passing. This aspect of the interplay between social dynamics and social statistics would be worth further exploration.

With the political debates on ethnicity and immigration increasing in volume in the face of new waves of refugees in Europe, political campaigns in the USA, and rising awareness of ethnic identity, this book is very topical and is an interesting addition to any library.

\section{Reference}

Simon, P., and Piché, V. 2013. Accounting for Ethnic and Racial Diversity: The Challenge of Enumeration. New York: Routledge.

2. Chapter 9 on Uruguay, by Wanda Cabella and Rafael Porzecanski.

3. Chapter 12 on Aboriginal populations in Canada, by Éric Guimond, Norbert Robitaille, and Sacha Senecal.

4. Chapter 10 on Belgium, by Nicholas Perrin, Luc Dal, and Michel Poulain.

5. Chapter 8 on Malaysia, by Shyamala Nagaraj, Tey Nai-Peng, Ng Chiu-Wan, Lee Kiong-Hock, and Jean Pala. 